Available online at GSC Online Press Directory

GSC Biological and Pharmaceutical Sciences

e-ISSN: 2581-3250, CODEN (USA): GBPSC2

Journal homepage: https://www.gsconlinepress.com/journals/gscbps

(RESEARCH ARTICLE)

\title{
Evaluation of the antioxidant activity of the bioactive components in an aqueous extract of Urtica dioica L leaves from eastern Algeria
}

\author{
Leila Derradji ${ }^{1,}{ }^{*}$, Ouided Saidi ${ }^{1}$ and Youcef Hadef ${ }^{2}$ \\ ${ }^{1}$ Laboratory of Pharmacognosy, Department of Pharmacy, Faculty of Medicine, Badji Mokhtar-Annaba University, \\ Algeria. \\ ${ }^{2}$ Laboratory of Development and Control of Pharmaceutical Preparations, Department of Pharmacy, Faculty of Medicine, \\ Badji Mokhtar-Annaba University, Algeria.
}

Publication history: Received on 08 July 2020; revised on 17 July 2020; accepted on 24 July 2020

Article DOI: https://doi.org/10.30574/gscbps.2020.12.1.0215

\begin{abstract}
Urtica dioica $\mathrm{L}$ is a spontaneous herb that is used in traditional medicine in Algeria. Numerous studies confirm the important pharmacological properties. Our study includes the evaluation of the antioxidant activity of the bioactive components of Urtica dioica L. The objective of our study is to highlight the importance of this plant which could be used in herbal medicine to fight against certain types of cancer. The antioxidant activity is evaluated by the 2, 2-diphenyl-1picryl hydrazyl (DPPH) trapping method. The results obtained show us that the leaves of Urtica dioica L. have a high antioxidant activity with $\mathrm{IC}_{50}$ of 0.4 milligram / milliliter.
\end{abstract}

Keywords: Urtica dioica; Leaves; Aqueous extract; Bioactive components; Antioxidant activity

\section{Introduction}

Urtica dioica $\mathrm{L}$ is a spontaneous herb that is used in traditional medicine in Algeria. Numerous studies confirm the important pharmacological properties. Our study includes the evaluation of the antioxidant activity of the bioactive components of Urtica dioica L. The leaves of this plant are rich in proteins and carbohydrates [1]. Among the phenolic compounds contained in nettle leaves are chlorogenic acid (trans-5-0-caffeylquinic), ferulic acid and 2-0-caffeylmalic acid [2]. We also note the presence of carotenoids, the amount of which varies according to the maturity of the leaf as well as the presence of $\alpha$-linolenic acid, which is the predominant fatty acid in mature leaves) [3].

The objective of our study is to highlight the importance of the therapeutic use of this which could be used as herbal medicine against some types of cancers. The evaluation method that we recommended is that of the reduction of the free radical 2, 2-diphenyl-1-picryl hydrazyl (DPPH) by an antioxidant (anti-free radical), followed by UV-Visible spectrometry, by measuring the decrease in l absorbance. In the presence of free radical scavengers, DPPH of purple color is reduced to 2.2 Diphenyl 1 picryl hydrazine of yellow color [4].

\section{Material and methods}

\subsection{Plant material}

In order to carry out our study, we harvested Urtica dioica L in eastern Algeria, in the outer harbor region in the eastern Algeria. The freshly harvested leaves are dried in the shade in a dry, ventilated place for two weeks.

\footnotetext{
${ }^{*}$ Corresponding author: Leila Derradji
} 


\subsection{Preparation of aqueous extracts}

We put 10 gram of the studied parts (the leaves) in $100 \mathrm{ml}$ of distilled water in an Erlenmeyer flask in a double boiler or on a hot plate at $t^{\circ}=200 \mathrm{C}^{\circ}$ for $20 \mathrm{~min}$. Once the extract is ready, we filtered twice with filter paper, we centrifuged the decoction for $5 \mathrm{~min}$ at 2000 gram. The storage of the recovered supernatant was in sterile vice tubes in the refrigerator $\left(4-6^{\circ} \mathrm{C}\right)$ to avoid any risk of degradation of the extracts due to the action of air.

\subsection{DPPH test protocol}

In order to determine the antioxidant power of the extracts of the leaves and root of Urtica dioica L, we used the DPPH trapping method (2, 2 DiPhenyl-1-Picryl-Hydrazyle).

\subsubsection{Preparation of the dilution of $D P P H$}

We prepared the DPPH solution by dissolving 2 milligram $(\mathrm{mg})$ of DPPH in 50 milliliter $(\mathrm{ml})$ of methanol. The preparation must be done at least 2 hours in advance for a good solubilization.

\subsubsection{Preparation of dilutions of the extract of the leaves of Urtica dioica in methanol}

We have prepared the dilutions of our extract at different concentrations: $0.1 \mathrm{mg} / \mathrm{ml}, 0.2 \mathrm{mg} / \mathrm{ml}, 0.4 \mathrm{mg} / \mathrm{ml}, 0.8 \mathrm{mg} / \mathrm{ml}$, $1.6 \mathrm{mg} / \mathrm{ml}, 2.5 \mathrm{mg} / \mathrm{ml}$, and $10 \mathrm{mg} / \mathrm{ml}$ (Table 1 ).

\section{SS: Stock Solution.}

DS: Diluted Solution

$\mu$ : microliter

Table 1 Dilutions of the extract of the leaves of Urtica dioica L in methanol

\begin{tabular}{lcc}
\hline Solution & Concentration $\mathbf{~ m g} / \mathbf{m l}$ & Preparing for dilution \\
\hline SS & $100 \mathrm{mg} / \mathrm{ml}$ & \\
\hline DS 1 & 0.1 & $1 \mu \mathrm{l} \mathrm{SS}+999 \mu \mathrm{l}$ methanol \\
DS 2 & 0.2 & $2 \mu \mathrm{l} \mathrm{SS}+998 \mu \mathrm{l}$ methanol \\
DS 3 & 0.4 & $8 \mu \mathrm{l} \mathrm{SS}+992 \mu \mathrm{l}$ methanol \\
DS 4 & 0.8 & $16 \mu \mathrm{l} \mathrm{SS}+984 \mu \mathrm{l}$ methanol \\
DS 5 & 1.6 & $25 \mu \mathrm{l} \mathrm{SS}+975 \mu \mathrm{l}$ methanol \\
DS 6 & 2.5 & $100 \mu \mathrm{l} \mathrm{SS}+900 \mu \mathrm{l}$ methanol \\
DS 7 & 10 & \\
\hline
\end{tabular}

\section{Results and discussion}

After preparing the dilutions of the extracts in methanol, we took $25 \mu \mathrm{l}$ of each extract which we put in a tank and added $975 \mu \mathrm{l}$ of the DPPH solution. The reaction mixture is immediately stirred before being placed in the dark for 60 minutes at room temperature. The absorbance of the reaction medium was measured at 517 nanometer (nm) using a spectrophotometer against a negative control (containing methanol instead of the extract).

\subsection{DPPH radical reduction results}

After adding the DPPH solution to our various dilutions, we stirred the reaction mixture immediately before being placed for $60 \mathrm{~min}$ in the dark and at room temperature in the laboratory. The results obtained are as follows: According to the preliminary result, the reaction of the DPPH solution with dilutions of the extract of the leaves of Urtica dioica L is positive. We observe the change in the purple color of the DPPH solution in yellow color, this indicates that the DPPH is reduced to 2.2 Diphenyl 1 picryl hydrazine by the presence of free radical scavengers in the extract of Urtica dioica $\mathrm{L}$. This reduction capacity is determined by a decrease in absorbance induced by anti-free radicals (Figure 1 ). 


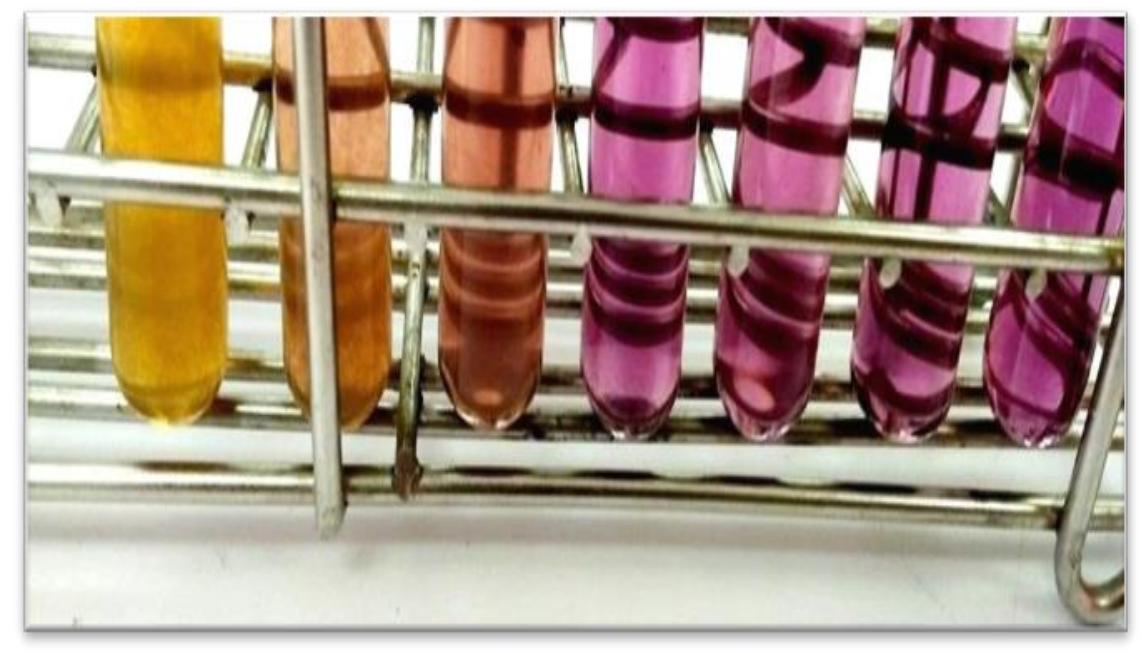

Figure 1 Reaction of the DPPH solution with dilutions of the extract of the leaves of Urtica dioica L.

\subsection{Expression of absorbance results by spectrophotometer}

To properly assess the antioxidant activity of the extract prepared from nettle leaves, we carried out the absorbance measurement at $517 \mathrm{~nm}$ using a reaction mixture spectrophotometer obtained after 1 hour of rest. This test is carried out with a negative control which contains only the methanoic solution of DPPH (975 $\mu$ l DPPH solution $+25 \mu \mathrm{l}$ methanol). The percentage of inhibition (I \%) of the DPPH radical by our extract is calculated as according to the formula:

$\mathrm{I} \%=[(\mathrm{A} 1-\mathrm{A} 2) / \mathrm{A} 1] \times 100$.

A1: Absorbance in the absence of the extract $=$ negative control (inhibitor)

\section{A 2: Absorbance in the presence of the extract}

The $\mathrm{IC}_{50}$ (50\% Inhibition Concentration) is the concentration of the tested sample necessary to reduce $50 \%$ of the DPPH radical. The $\mathrm{IC}_{50}$ are calculated graphically by percentages of inhibition as a function of the different concentrations of the extracts tested. The results we have obtained are expressed in relation to those obtained for ascorbic acid which represents the reference antioxidant (Figure 2).

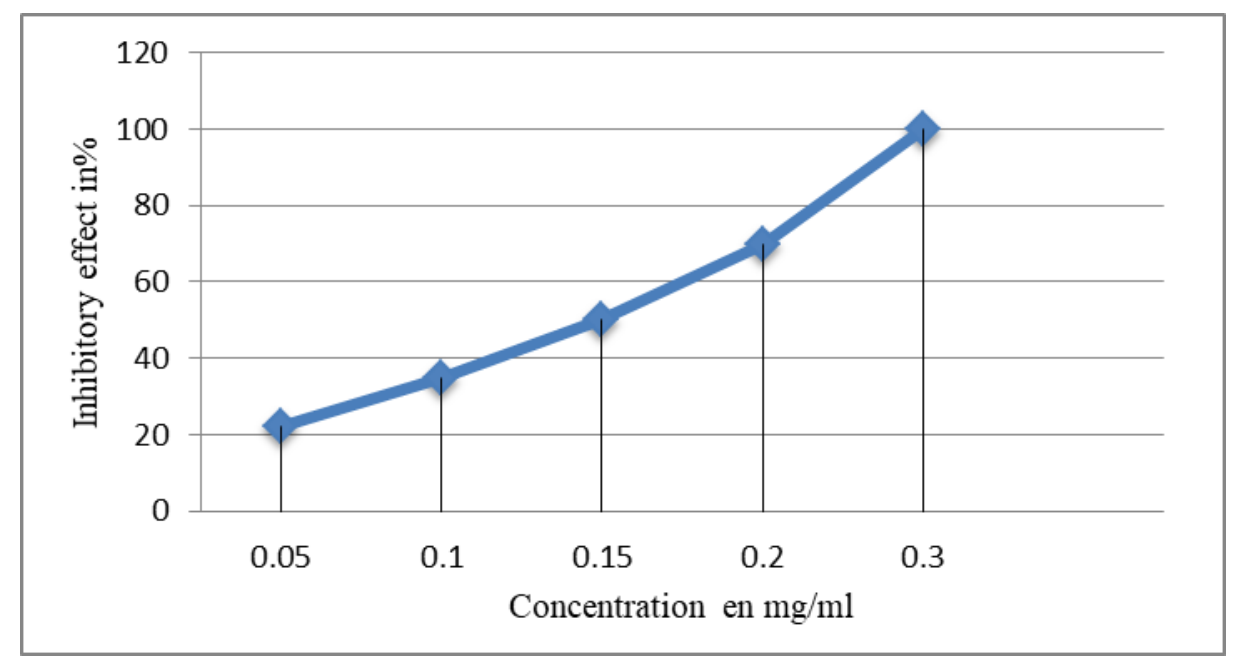

Figure 2 Curve representing the activity of ascorbic acid (reference antioxidant). 
The results obtained from the aqueous extract tested from the leaves of Urtica dioica L show that the percentage of inhibition is greater than $90 \%$ at a concentration of the order of $2 \mathrm{mg} / \mathrm{ml}$. There is total inhibition of the extract tested at a concentration of the order of $2.5 \mathrm{mg} / \mathrm{ml}$. The aqueous extract of nettle leaves has a high antioxidant power with IC 50 is $0.4 \mathrm{mg} / \mathrm{ml}$, relatively slightly low but remains close to that of ascorbic acid, the value of which is around $0.134 \mathrm{mg} / \mathrm{ml}$ (Figure 3).

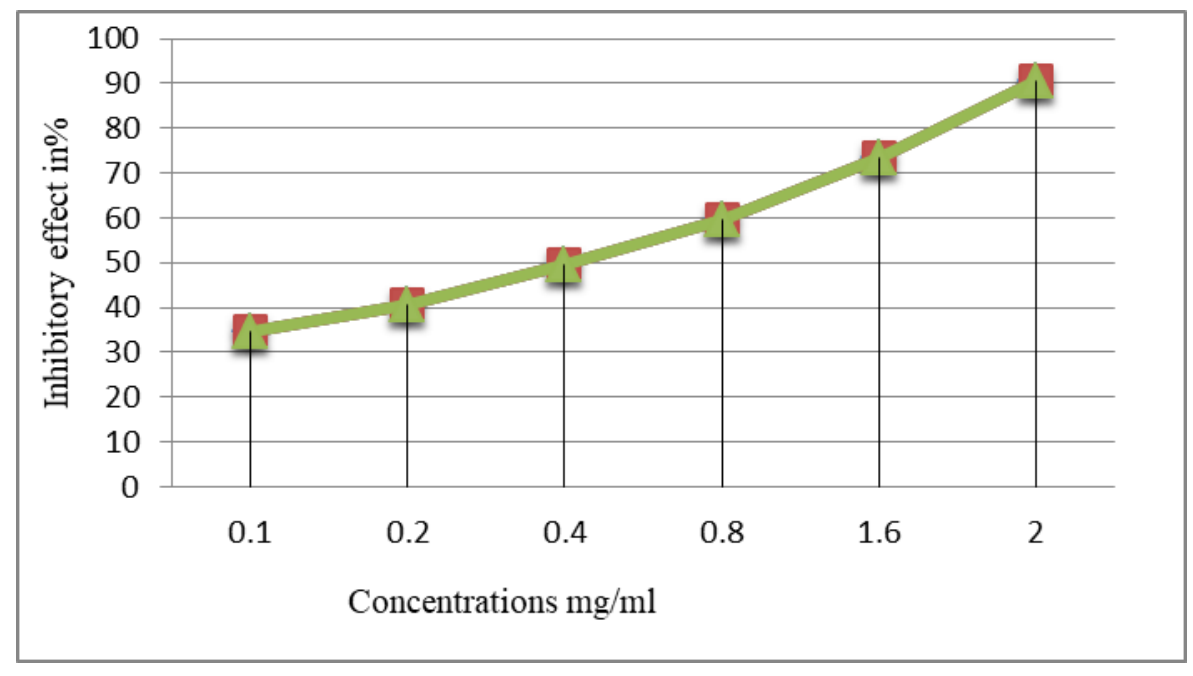

Figure 3 Courbe représentatif de l'activité d'extrait des feuilles d'Urtica dioica L.

« Güler [5] have obtained similar results on two types of maceration (aqueous and acid) of leaves Urtica dioica leaves from Turkey, with $\mathrm{IC}_{50}$ similar to ours: 0.30 and $0.37 \mathrm{mg} / \mathrm{ml}$ respectively for the aqueous and acid maceration of this plant ». Dall'Acqua and al [6] obtained slightly different results from ours since, on the methanolic extract of Urtica dioica leaves from Italy, recorded the weakest activity with respect to the DPPH radical with IC50 of $419 \mu \mathrm{g} / \mathrm{ml}$ compared to the other extracts from the same region».

\section{Conclusion}

The antioxidant activity tested in the aqueous extract of leaves of Urtica dioica L was carried out by the DPPH trapping method. From the results obtained, we can conclude that the leaves of Urtica dioica L have significant antioxidant activity. This antioxidant property should give this plant a place in herbal medicine, especially against certain forms of cancer.

\section{Compliance with ethical standards}

\section{Acknowledgments}

We thank the personal manager of the analytical chemistry laboratory for allowing us to perform the dosage and we thank the staff for helping us in handling the tests performed.

\section{Disclosure of conflict of interest}

All authors declare that we participated in the design, execution and analysis of the document and that I approve the final version. In addition, there is no conflict of interest in connection with this document, and the material described is not in the process of being published nor is it intended for publication elsewhere.

\section{References}

[1] Couplan F. (2011). Guide nutritionnel des plantes sauvages et cultivées. Paris: Delachaux et Niestlé, 256.

[2] Orčić D, Francišković M, Bekvalac K, et al. (2014). Quantitative determination of plant phenolics in Urtica dioica extracts by high-performance liquid chromatography coupled with tandem mass spectrometric detection. Food Chemistry, 143, 48-53. 
[3] Guil-Guerrero J, Rebolloso-Fuentes M and Isasa M. (2003). Fatty acids and carotenoids from Stinging Nettle (Urtica dioica L). Journal of Food Composition and Analysis, 111-119.

[4] Molyneux P and Songklanakarin J. (2004). The use of the stable free radical diphenylpicrylhydrazyl (DPPH) for estimating antioxidant activity. Sciences technology, 212-218.

[5] Güler E. (2013). Investigation of Chemopreventif Properties of Urtica dioica L, in MCF-7 and MDA 231 Breast Cancer Cell Lines. The New Journal of medicine, 50-53.

[6] Dall'Acqua S, Cervellati R, Loi M and Innocenti G. (2008). Evaluation of in vitro antioxidant properties of some traditional Sardinian medicinal plants: Investigation of the high antioxidant capacity of Rubus ulmifolius. Food Chemistry, 745-749.

\section{How to cite this article}

Leila D, Ouided S and Youcef H. (2020). Evaluation of the antioxidant activity of the bioactive components in an aqueous extract of Urtica dioica L leaves from eastern Algeria. GSC Biological and Pharmaceutical Sciences, 12(1), 235-239. 